properly speaking, dynamics at all. However, the analysis of every dynamical problem must begin with a thorough kinematic investigation, and when this has been made and the results assimilated, the application of the truly dynamical principles is usually easy. In my opinion, the importance of kinematics has been greatly under-estimated in recent times. It is therefore pleasing to find that due attention to kinematics is paid in this treatise. The first chapters cover basic kinematics, the dynamics of a particle and the dynamies of sets of particles. Next, Chapters 4-7 give an outline of the kinematics and dynamics of fluids, with sections on vortices and the application of the complex variable, while Chapters 8-9 are concerned with the theory of aerofoilin two and three dimensions. Chapter 10 deals very briefly (and it must be said, too briefly) with viscosity, turbulence and the applications of dimensional analysis. The next two chapters are concerned with the kinematics and dynamics of rigid bodies, and the final chapters deal with the oscillations of dynamical systems having one or a larger finite number of degrees of freedom.

I can sum up my opinion of this book by saying that it gives a competent account of basic dynamics for students of aeronautical engineering from the point of view of one experienced teacher. Many readers will be disappointed to find that the more advanced topics of aeronautical dynamics, such as the theories of stability and control and of flutter, are not discussed at all. The title of the book is, indeed, rather misleading in this respect.

W. J. Duncan

\section{THE ADVANCE OF PLANT PHYSIOLOGY}

Annual Review of Plant Physiology

Fdited by Daniel I. Arnon, in association with Leonard Machlis. Vol. 5. Pp. x +400 . (Stanford, Calif.: Annual Reviews, Inc., 1954.) 7 dollars.

$\mathrm{W}$ ITH the publication of its fifth volume the "Annual Review of Plant Physiology" may claim to be well established. The present volume follows the same lines as its predecessors and contains fourteen articles on different aspects of plant physiology. While some of these cover a wide field, such as that on tropisms and nastic movements (L. Brauner), or deal with subjects of considerable appeal to plant physiologists, such as the long article on photosynthesis (R. Lumby, J. D. Spikes and H. Eyring) with no less than 401 references, that on the connected subject of the photosynthetic function of pigments other than chlorophyll (L. R. Blinks) and the one on the occurrence, formation and inactivation of auxins (S. A. Gordon), others deal with matters of which knowledge is perhaps not so widely distributed, even among plant physiologists. Among such might be included the articles on the physiology of plant tumours (A. C. Braun), dormancy in woody plants (R. M. Samish), the post harvest physiology of fruits and vegetables (W. T. Pentzer and P. H. Heinze), the physiological aspects of fungus diseases of plants (P. J. Allen), and the role of plant physiology in plant geography (H. L. Mason and P. R. Stout). Yet, with the exception of the last-named, none of these articles has less than a hundred references to literature.
Of the subjects dealt with in the present volume, perhaps those in which advances in knowledge are most spectacular concern enzymes. One of these, by W. D. MeElroy and A. Nason, is on micronutrient elements in enzyme systems; the other, by D. A. Goddard and H. A. Stafford, deals with the localization of enzymes in the cells of higher plants. A perusal of these reviews cannot fail to impress on the reader the real progress that has been made in these subjects during the past few years. Thirty years ago, that such things as trace elements were essential for plants had scarcely been accepted by plant physiologists in general. Ten years ago, by which time the necessity for trace elements was well recognized, their function was obscure and a matter for conjecture. The article by McElroy and Nason now shows strikingly how widespread is the necessity for one or other of these elements for the activation of enzymes. Iron and copper enzyme systems, as well as some involving magnesium, have been known for some time, but now McElroy and Nason list more than twenty enzymes which are activated by manganese, and they conclude that manganese is the chief metal concerned in general enzymatic decarboxylation and hydrolysis. Zine and magnesium appear to be similarly involved to some extent. Manganese, though not to the same extent as magnesium, appears also to be required for enzyme actions involving group transference. Copper, iron and molybdenum are concerned with electrontransferring systems.

A few years ago knowledge of the subject here dealt with by Goddard and Stafford was negligible. Now at the end of their article on the localization of enzymes in the cell they list 101 references, 90 per cent of which refer to publications that have appeared not earlier than 1950. The extension of knowledge of enzyme systems to include their localization in the cell has resulted from the new technique of differential centrifugation of cell-free homogenates, by which a partial separation at least of cell constituents such as nuclei, plastids, mitochondria and microsomes is attempted. While the authors of the review show that the results so far obtained must be accepted with caution, it seems clear that the development of this line of investigation gives promise of information of the greatest importance in the not distant future.

Another article dealing with a new development is that on soil conditioners by J. H. Quastel. While the importance of the natural soil conditioner, humus, has been known for centuries and, maybe, thousands of years, it is only during the past few years that the possibility of using synthetic substances for improving poorly aggregated soils has been indicated. This article gives a clear account of the nature of the synthetic soil conditioners and their effects on soil, and will be read with interest by pedologists as well as by plant physiologists.

The remaining two articles are on nutrition by foliar application (D. Boynton), and the mineral nutrition of phytoplankton (B. H. Ketchum). The former, concerned as it is with the effect of sprays, will be of particular interest to pomologists, while the latter will be of special appeal to that growing band of physiologists who use unicellular algae, as providing reproducible material, for their investigations. Once again the editors and contributors are to be congratulated on providing for their fellow plant physiologists a most useful and welcome volume.
WALTER STILES 